\title{
Ageing People Living with HIV: Impact on Healthcare
}

\section{Dear Editor,}

A ccording to World Health Organization, Human Immunodeficiency Virus (HIV) is an infection of the immune system by retrovirus and lead to impair the function of immune system. World Health Organization has classified Malaysia as concentrated HIV epidemic which is spread from most-at-risk populations especially among illicit drug users, sex workers and transgender population. As of December 2013, Ministry of Health of Malaysia surveillance data reported that a cumulative of 101,672 HIV cases with an estimated 3,393 new HIV cases detected(Ministry of Health Malaysia, 2014).Globally, about $21 \%$ or 8575 of estimated 47,352 HIV people in the United State were at the age of 50 and over. From this age group, about 3747 peoples were those at the aged of 50 to 54 (Center for Disease Control and Prevention, 2015).Due to the introduction of Highly Active Antiretroviral Therapy (HAART) in 1998, there was a reduction in the number of AIDS-related death and increase the expectation of life for people living with HIV (PLHIV) (Unicef Malaysia). HAART is a combination of nucleoside reverse transcriptase inhibitors, non-nucleoside reverse transcriptase inhibitors, and protease inhibitors. HAART is effective to prevent virus HIV replication, thus led to increase life span of PLHIV with an improved quality of life (Hammer et al., 2008). PLHIV can live up to an age over 60 years which also termed as an 'elderly'. Growing older with HIV is an unexpected challenge for PLHIV because they undergo a condition called premature aging.

For normal people, physiological aging occurs mainly due to oxidative stress and result in damage of the cells; however, prolonged exposure to HIV tends to accelerate natural aging process (Torres and Lewis, 2014). Long term effect of HIV infection may increase risk and impact to cardiovascular and metabolic disorder such as insulin resistance, impact on lipid

\section{Saliza Ibrahim ${ }^{1,2}$, Sarahfarina Abd Rahim ${ }^{1,2}$, Long Chiau Ming ${ }^{1,3 *}$ \\ ${ }^{1}$ Faculty of Pharmacy, Universiti Teknologi MARA, Puncak Alam, Selangor, Malaysia. ${ }^{2}$ Pharmaceutical Services Divisions, Selangor, Malaysia. ${ }^{3}$ Brain Degeneration and Therapeutics Group, Pharmaceutical and Life Sciences CoRe, Universiti Teknologi MARA, Shah Alam, Malaysia.}

*Corresponding Author:

Email: saliza.ibrahim54@gmail.com; ming.long @ bath.edu

Tel: +603 32584775; Fax: +603 32584602 profile and lipodystrophy (Kotler, 2008). Even though HAART has been utilized to reduce mortality and morbidity, there was an increase rate of death due to non-AIDS related illnesses or due to non-communicable diseases such as liver disease, lung cancer, renal impairment, cognitive impairment, osteoporosis and nonAIDS malignancies (Cardoso et al., 2013).

Treatment and care for HIV patient may be complicated due to the prevalence of co-morbidities and non-communicable diseases. Furthermore, co-administration of multiple drugs in addition to HAART may lead to increase pill burden, potential drug-drug interaction and adverse effect, and loss of treatment efficacy and virological breakthrough (Nachega et al., 2012).

The HIV and Aging Consensus Project initiated by the American Academy of HIV Medicine, which has created a clinical management for practitioners purposely for aging population with HIV. This guideline supported by American Geriatrics Society (AGS) and other organization is to guide the practitioners on managing ageing people with co-morbidities and HIV infection. Ministry of Health of Malaysia has developed a Guideline for the Management of Adult HIV with antiretroviral therapy. However, this guideline was lack of information about specific management for ageing people living with HIV.

Ministry of Health of Malaysia also has prepared the National Strategic Plan (NSP) on HIV/AIDS 2006-2010. This plan provided an integrated approach in order to identify the needs and support which involve multi-sectoral engagement to deliver the healthcare services and ARV treatment. Some of the strategies used were multi-sectoral engagement in HIV response; ARV treatment, resource mobilization; harm reduction program; mother-to-child transmission prevention; mobilization of the most at risk population; engagement with religious leaders and improvement to provide a quality information and report regarding HIV epidemic (Ministry of Health Malaysia, 2011).

Subsequently, Malaysia National Strategic Plan on HIV and AIDS 2011-2015 has been developed to prevent the spread of HIV risk and infection. Besides that, the objective of NSP 20012015 are to increase quality of life for PLHIV and lessen impact of social and economic from HIV and AIDS. One of the strategies is to increase the access of care and support for PLHIV and provide the quality of testing and treatment (Ministry of Health Malaysia, 2011). Malaysia is a country that provide ARV treatment in all government hospitals and community clinics. As December 2013, 
about 17,369 PLHIV already treated with ARV treatment (Ministry of Health Malaysia, 2014). Besides that, in order to ensure the care and support of treatment for PLHIV, Ministry of Health of Malaysia has to provide a better counseling services for people those in need of treatment, increase an adherence to ARV treatment, improve detection if treatment failure happened and provide adequate training for healthcare providers for better services (Ministry of Health Malaysia, 2011). In 2013, Hospital Peer Support Program conducted with Partner Organization has served about 2708 people who live with HIV by providing the peer support counseling and ensure adherence to ARV. This collaboration also provided shelter home and support from religious bodies especially for homeless people living with HIV (Ministry of Health Malaysia, 2014).

\section{CONCLUSIONS}

When HIV was first discovered in 1980s, the prognosis of the patients infected was very poor. With the advancement of treatment, the high hopes of the infected individuals for longer life expectancy and better quality of life can be achieved. Nevertheless, Ministry of Health of Malaysia and private sector stakeholders has to continuously provide medication and healthcare support in order to improve quality of life and treatment outcomes of ageing PLHIV.

\section{REFERENCES}

Cardoso SW, Torres TS, Santini-Oliveira M, et al. Aging with HIV: a practical review. Braz J Infect Dis, 2013;17, 464-79.

Center for Disease Control and Prevention. HIV Among People Aged 50 and Over. Available: http://www.cdc.gov/hiv/ group/age/olderamericans/index.html. Accessed 10 Nov 2015.
Hammer SM, Eron JJ, Reiss P, et al. Antiretroviral treatment of adult HIV infection: 2008 recommendations of the International AIDS Society-USA panel. JAMA, 2008; 300, 555-70.

Kotler DP. HIV and antiretroviral therapy: lipid abnormalities and associated cardiovascular risk in HIV-infected patients. J Acquir Immune Defic Syndr, 2008; 49, S79-S85.

Ministry of Health Malaysia, National Strategic Plan on HIV and AIDS. 2011-2015, 2015.

Ministry of Health Malaysia. Global AIDS Response Progress Report 2014. Available: www.moh.gov.my/images/gallery/ Report/Country_health.pdf. Accessed 10 Nov 2015.

Nachega JB, Hsu AJ, Uthman OA, et al. Antiretroviral therapy adherence and drug-drug interactions in the aging HIV population. AIDS, 2012; 26, S39-S53.

Torres RA, Lewis W. Aging and HIV/AIDS: pathogenetic role of therapeutic side effects. Lab Invest, 2014; 94, 120-8.

Unicef Malaysia. UNICEF Global Malaysia AIDS Statistic Overview. Available: http://www.unicef.org/malaysia/UNICEF__Global_Malaysia_AIDS_Statistics_Overview_2010.pdf. Accessed 9 Nov 2015.

World Health Organisation, HIV/AIDS. Available: http://www.who.int/ topics/hiv_aids/en/.Accessed 10 Nov 2015. .

\section{How to cite this article:}

Ibrahim S, Rahim SA, Ming LC. Ageing People Living with HIV: Impact on Healthcare. J App Pharm Sci, 2016; 6 (01): 162-163. 